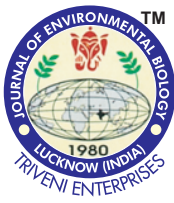

DOI : http://doi.org/10.22438/jeb/38/5(SI)/GM-09
Journal of Environmental Biology

ISSN: 0254-8704 (Print) ISSN: 2394-0379 (Online) CODEN: JEBIDP

\title{
Calculating landscape diversity with alpha diversity indices
}

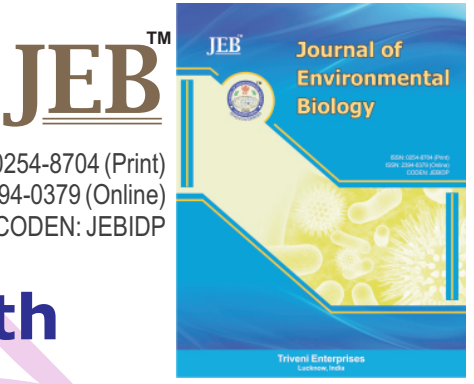

Authors Info

\section{Ö. Şentürk* and K. Özkan}

${ }^{1}$ Forestry Department, Gölhisar Vocational School, Mehmet Akif Ersoy University, Gölhisar, Burdur, 15400, Turkey

${ }^{2}$ Department of Forest Engineering, Faculty of Forestry, Süleyman Demirel University, Isparta, 32100, Turkey

\section{*Corresponding Author Email :} osenturk@mehmetakif.edu.tr

Key words

Beta diversity,

Diversity components,

Gamma diversity,

Kuyucak Mountain,

Shannon Wiener

Publication Info

Paper received : 16.08 .2016

Revised received : 20.06 .2017

Accepted : 26.06 .2017

\section{Abstract}

Aim: The fundamental information layers of ecosystem -based management plans are obtained by calculating, modeling and mapping of biodiversity. This study was carried out to calculate and map of landscape diversity in the Kuyucak Mountain District, in the transition zone of the Mediterranean region.

Methodology: Topographical diversity values of altitude, slope degree and radiation index for each cell $(752.09 \times 752.09 \mathrm{~m})$ of Kuyucak Mountain District were calculated using Shannon Wiener, Simpson diversity, Renyi $\mathrm{H}_{2}$ and Rao indices. The index for each variable topographic map, which was prepared using cellular values after the calculations was obtained by Geographic Information Systems.

Results: The maps illustrating diversities of topographical variables were prepared in order to obtain more accurate model - based distribution map of biodiversity.

Interpretation: Climate, topography and soil properties play important roles on biodiversity. There are also significant relationships between landscape diversity and biodiversity. That is why it is important to prepare not only climatic, topographic and soil maps but also diversity maps as explanatory variables for modeling and mapping of biodiversity.

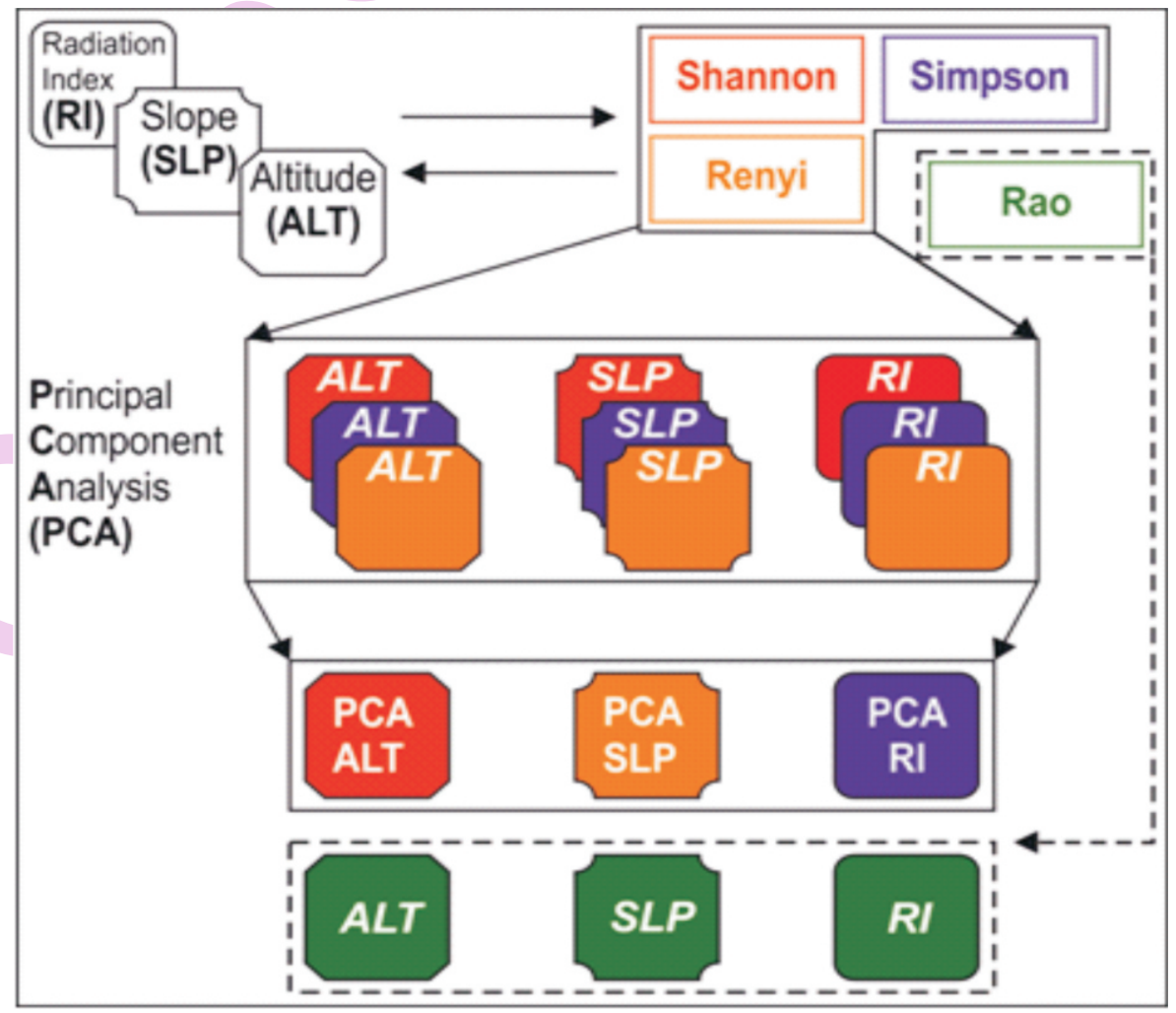




\section{Introduction}

Predictive distribution models (PDMs) have been increasingly used to visualize potential distribution areas of living entities such as birds (Manel et al., 1999; Brotons et al., 2004; Seoane et al.,2004; Ortega-Huerta and Peterson, 2008), plants (Ray et al., 2011; Rameshprabu and Swamy, 2015), wild animals (Munguía et al., 2008; Ahmadi et al., 2013; Kramer Schadt et al., 2013), insects (Tognelli et al.,2009; Habel et al., 2010; Dáttilo et al., 2012; Sobek-Swantet al.,2012; Filz and Schmitt, 2015; Sánchez-García et al., 2015), reptiles and amphibians (Guisan and Hofer, 2003; Arntzen, 2006; Franklin et al., 2009) in conservation biology, biogeography and forest ecology. Those models have been also used in mapping vegetation communities (Lees and Ritman, 1991; Dymond and Johnson, 2002; Boyden et al., 2013), ecological land classification (Blasi et al.,2000; Özkan et al., 2013; Grondin et al., 2014) and biodiversity (Özkanet al., 2016).

Creating a distribution model requires response data (inventory data, such as, vegetation types, biodiversity values and occurrence or productivity data of the species) and explanatory data (environmental variables composed of edaphic, topographic and climatic parameters). As for visualization of a distribution model, the main materials and tools are georeferenced data of the inventory points, digitalized environmental layers and geographical information systems.

Among the response variables for ecological modeling, biodiversity is of great importance because it is strongly related to balance, resilience, health and sustainability of the ecosystems (Özkan and Berger, 2014). Distribution maps of biodiversity are, therefore, vital for determining priority conservation areas or hotspots in a given ecosystem.

Biodiversity is measured at alpha, beta and gamma scales. Alpha diversity is measured at a single site although beta diversity is the amount of change among the sites. Gamma diversity is similar to alpha diversity, only measured on a large scale (Whittaker, 1972).

Environmental factors and environmental heterogeneity both are potentially decisive factors in the variation of biodiversity components, in particular variation of the beta diversity (Dufour et al.,2006; Veech and Crist, 2007). Therefore, preparation of the layers not only of environmental factors but also of representative parameters of environmental heterogeneity is important to design stronger and more accurate predictive distribution models of biodiversity. In this regard, various indices such as Shannon entropy and Simpson diversity index can be used (Shannon, 1948; Simpson, 1949).

In Turkey, Mediterranean forests generally occur in the mountainous and karstic areas. Hence, environmental heterogeneity is high in many of the forest areas and influences the geographical distribution of biodiversity (Özkan, 2006; Özkan, 2008; Özkan et al., 2010). Representative parameters of environmental heterogeneity should, therefore, be considered as explanatory variables together with the other environmental variables for modeling and mapping processes of biodiversity.

In the present study, conducted in the Kuyucak Mountain district located in the Mediterranean region, Turkey, an attempt was made to create diversity maps of altitude, radiation index and slope degree by using various diversity indices so that all potential explanatory variables influencing species diversity could be ready for a further study regarding modeling and mapping diversity of species that would be undertaken in the ongoing project in the district.

\section{Materials and Methods}

The study area, Kuyucak mountain district is located in the transition zone of the Mediterranean region $\left(37^{\circ} 21^{\prime} 06^{\prime \prime} \mathrm{N}-\right.$ $37^{\circ} 43^{\prime} 39^{\prime \prime} \mathrm{N}$ and $\left.30^{\circ} 51^{\prime} 15^{\prime \prime} \mathrm{E}-31^{\circ} 18^{\prime} 13^{\prime \prime} \mathrm{E}\right)$. Of its total land area of $930.5 \mathrm{sq} \mathrm{km}$, it is characterized by high mountainous areas $(37 \%)$, deep or shallow canyons $(42 \%)$, hills or upland $(10 \%)$, ridges (7\%) and plains (4\%).

An ongoing TUBITAK project (PN: 1130495) entitled "Spatial Modelling of Woody Plant Diversity in the Kuyucak Mountain District" was been carried out since the beginning of 2013 in the Kuyucak mountain district. The main purpose of the project was based on modeling and mapping of biodiversity components (alpha, beta and gamma diversities). In this context, 200 areas approximately in size of $\sim 752.09 \times 752.09 \mathrm{~m}$ corresponding to the cell size of BIOCLIM data (30 arc - second) (Hijmans et al., 2005) were selected and the plants species were recorded in four sample plots at each pixel of the BIOCLIM data (BIOPIXEL) in order to compute beta and gamma plant diversity so that those diversity components could be statistically correlated with the climatic data.

The district has four major mountain ranges: Sarp mountain (peak height: $2545 \mathrm{~m}$ ), Duran mountain (peak height: 2214), Erenler mountain (peak height: 2023) and Tota mountain (peak height: $1852 \mathrm{~m}$ ). The district, having a total of 478 species (Fabaceae, Asteraceae, Caryophyllaceae, Lamiaceae, Brassicaceae, Boraginaceae, Rosaceae, Apiaceae, Scrophulariaceae and Ranunculaceae) is rich in plant diversity (Özcelik and Korkmaz, 2002).

The most widespread bedrock is limestone. The others are sandstone, conglomerate, marn, dolomite, basalt and ophioliticmelange. The fact that beta diversity and gamma diversity may not be related not only to environmental factors, in particular climatic factors, but to environmental heterogeneity (Rocchini et al., 2010) madeus calculate the representative 
variables of environmental heterogeneity at each BIOPIXEL of the district. In this regard, the relevant maps were prepared by the following processes:

1. The values of altitude, radiation index and slope degree for each of 36 equally divided sub-pixels were determined at each BIOPIXEL by using Create Fishnet toolbox in ArcMap 10.1.

2. Shannon wiener $(H)$, Simpson diversity $(1-\lambda)$, Renyi $\left(H_{2}\right)$ and $\operatorname{Rao}(Q)$ indices were used to calculate diversity values of each of BIOPIXEL for each variable ${ }^{1}$. All the diversity measures were then visualized for each of the topographical variables.

3. Correlation analysis was performed among diversity indices for each variable. PCA was then applied to produce a component diversity map for each of the variables (Özdamar, 1999).

Altitude and slope degree were directly calculated from digital elevation model by using ArcMap 10.1. Radiation index (RD) was calculated by the following equation (Moisen and Frescino, 2002; Aertsen et al., 2010; Wei et al.,2010).

$$
\mathrm{RD}=\frac{\left[1-\cos \left(\left(\frac{\pi}{180}\right)(\theta-30)\right)\right]}{2}
$$

where, $\theta$ is a value which is measured from the north aspect. This equation's result changes between 0 and 1 .

Shannon wiener (H) (Shannon, 1948), Simpson diversity (1- $\lambda)$ (Simpson, 1949), Renyi $\left(\mathrm{H}_{2}\right)$ (Renyi, 1961) and Rao (Q) (Rao, 1982; Botta-Dukat, 2005; Ricotta, 2005) indices were calculated by the following equations:

$$
H=-\sum_{i=1}^{n} p_{i} n p_{i}
$$

where, $p i$ is the proportion value of sub-pixels and $n$ is sub-pixels diversity.

$$
1-\lambda=-\sum_{i=1}^{n} p_{i}^{2}
$$

where, $\lambda$ is the Simpson dominance index, $p i$ is the proportion value of sub-pixels.

$$
H_{2}=\frac{1}{1-\alpha} \ln \Sigma p^{\alpha}
$$

In the equation, $H_{a}=H_{2}(\alpha=2)$, therefore, $H_{2}=\ln (1 / \lambda)$ where, $\lambda$ is the Simpson Dominance index (Rocchini etal., 2013).

$$
Q=\sum_{i=1}^{n} \sum_{j=1}^{n} d_{j} p_{i} p_{j}
$$

where, $n$ is the number of sub-pixels, $p i$ is the proportion value of sub-pixels, dij is dissimilarity of sub-pixels between $i$ and $j$.

\section{Results and Discussion}

Maps of diversity measures of topographical variables, i.e., altitude (ALT), slope degree (SLP) and radiation index (RI), are given in Fig. 1. Fig. 1 shows some maps resemble each other because there are high correlations among some indices. According to the results of the applied Pearson correlation analyses between $\mathrm{H}$ and $1-\lambda$ maps for each of the topographic variables, all the correlation coefficients were positive and had " $\mathrm{r}$ " values more than 0.90 . In addition to this, $\mathrm{H}_{2}$ maps were negatively and strongly associated with $\mathrm{H}$ and $1-\lambda$ maps $(r<0.90)$ for each of all topographical variables (Table 1). However, Q maps were weakly related to $\mathrm{H}, \mathrm{H}_{2}$ and $1-\lambda$ maps (Table 1).

Correlation analysis shows that combining of $\mathrm{H}, 1-\lambda$ and $\mathrm{H}_{2}$ maps for each of the topographical variables is required due to their strong interrelations (Table 1). For this purpose, PCA was applied to create a component parameter from those diversity measures for each topographic variable. PCA results are given in Table 2 .

As expected, the first axes of the applied PCA ALT $_{1}, \mathrm{PCA}_{\text {SLP, }}$ and $P C A_{R 1}$ explained high percentage of total variance. It means that first axes represent $\mathrm{H}, 1-\lambda$ and $\mathrm{H}_{2}$ measures for each of ALT, SLP and RI. The constants and the coefficients belonging to the

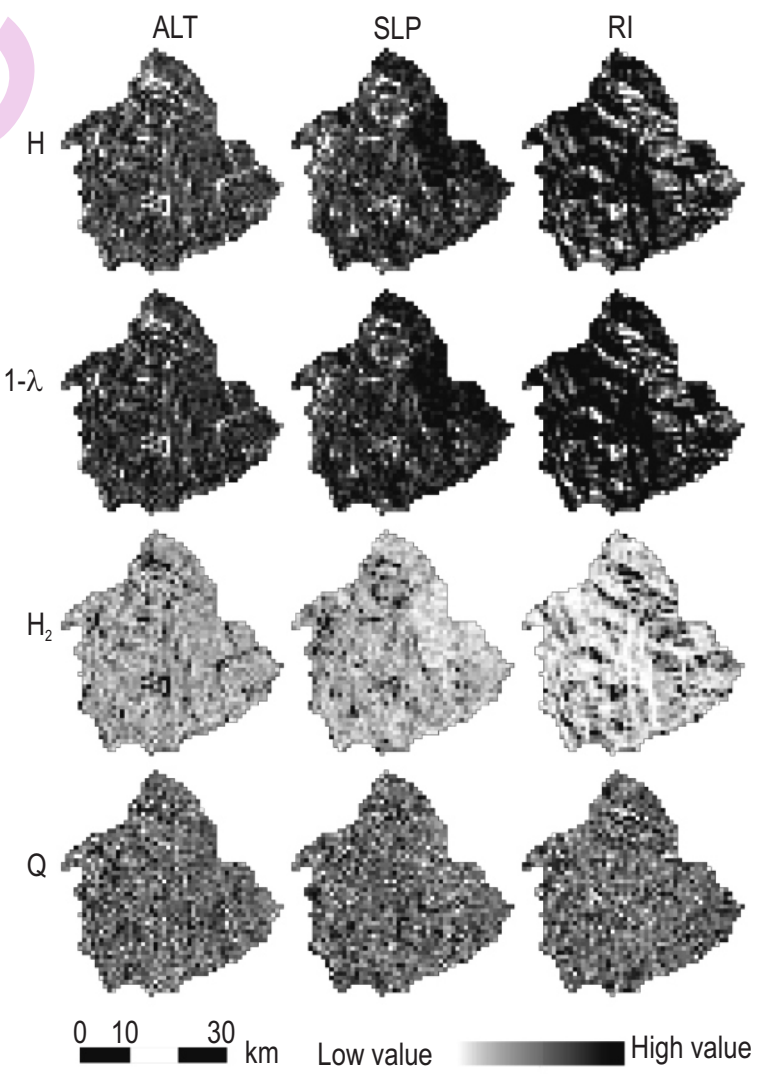

Fig. $1: \mathrm{H}, \mathrm{H}_{2}, 1-\lambda$ and $Q$ maps of ALT, SLP and RI in the Kuyucak Mountain District 
Table 1 : The results of correlation analysis among diversity maps of ALT, SLP and RI ( $n=2107, p<0.001$ if $r>0.072)$

\begin{tabular}{|c|c|c|c|c|}
\hline & $\mathrm{H}_{\mathrm{ALT}} ; \mathrm{H}_{\mathrm{SLP}} ; \mathrm{H}_{\mathrm{RI}}$ & $1-\lambda_{\mathrm{ALL}} ; 1-\lambda_{\mathrm{SLP}} ; 1-\lambda_{\mathrm{RI}}$ & $\mathrm{H}_{2 \mathrm{ALT}} ; \mathrm{H}_{2 \mathrm{SLP}} ; \mathrm{H}_{2 \mathrm{RI}}$ & $Q_{\mathrm{ALT}} ; \mathbf{Q}_{\mathrm{SLP}} ; \mathbf{Q}_{\mathrm{RI}}$ \\
\hline $\begin{array}{l}\mathrm{H}_{\mathrm{ALT}} ; \mathrm{H}_{\mathrm{SLL}} ; \mathrm{H}_{\mathrm{RI}} \\
1-\lambda_{\mathrm{ALL}} ; 1-\lambda_{\mathrm{SL}} ; 1-\lambda_{\mathrm{RI}} \\
\mathrm{H}_{2 \mathrm{ALT}} ; \mathrm{H}_{2 \mathrm{SLL}} ; \mathrm{H}_{2 \mathrm{RI}} \\
\mathrm{Q}_{\mathrm{ALT}} ; \mathrm{Q}_{\mathrm{SLP}} ; \mathrm{Q}_{\mathrm{RI}}\end{array}$ & $\begin{array}{l}1 ; 1 ; 1 \\
0.925 ; 0.965 ; 0.935 \\
-0.910 ;-0.958 ;-0.921 \\
-0.247 ;-0.216 ;-0.178\end{array}$ & $\begin{array}{l}0.925 ; 0.965 ; 0.935 \\
1 ; 1 ; 1 \\
-0.999 ;-0.999 ;-0.999 \\
-0.044 ;-0.101 ; 0.021\end{array}$ & $\begin{array}{l}-0.910 ;-0.958 ;-0.921 \\
-0.999 ;-0.999 ;-0.999 \\
1 ; 1 ; 1 \\
0.034 ; 0.094 ;-0.032\end{array}$ & $\begin{array}{l}-0.247 ;-0.216 ;-0.178 \\
-0.044 ;-0.101 ; 0.021 \\
0.034 ; 0.094 ;-0.032 \\
1 ; 1 ; 1\end{array}$ \\
\hline
\end{tabular}

Table 2 : The results of PCA analyses for each of ALT, SLP and RI using $\mathrm{H}, 1-\lambda$ and $\mathrm{H}_{2}$ data

\begin{tabular}{llll}
\hline & Eigenvalue & \% of Variance & Cum.\% of Var. \\
\hline PCA $_{\text {ALT }}$ (Axis: $\left.1 ; 2 ; 3\right)$ & $(2.889 ; 0.110 ; 0.000)$ & $(96.311 ; 3.681 ; 0.008)$ & $(96.311 ; 99.992 ; 100.00)$ \\
$\mathrm{PCA}_{\text {SLP }}($ Axis: $1 ; 2 ; 3)$ & $(2.949 ; 0.0 .051 ; 0.000)$ & $(98.292 ; 1.700 ; 0.008)$ & $(98.292 ; 99.992 ; 100.00)$ \\
$\mathrm{PCA}_{\text {RI }}$ (Axis: $\left.1 ; 2 ; 3\right)$ & $(2.904 ; 0.096 ; 0.000)$ & $(96.785 ; 3.207 ; 0.008)$ & $(96.785 ; 99.992 ; 100.00)$ \\
\hline
\end{tabular}

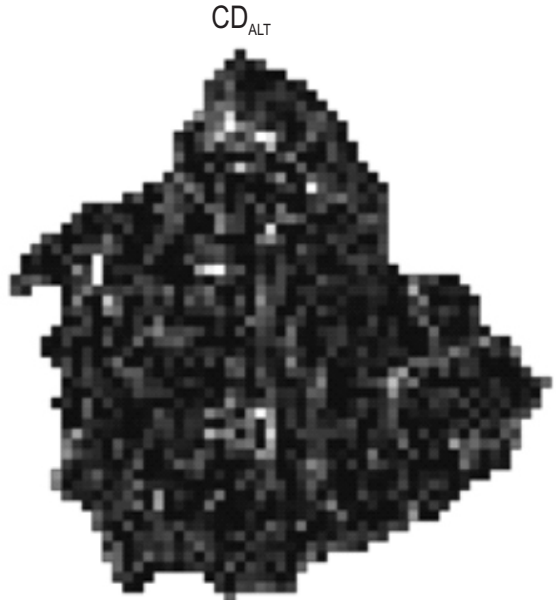

0

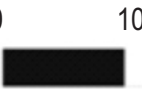

10

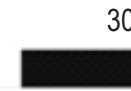

$\mathrm{km}$

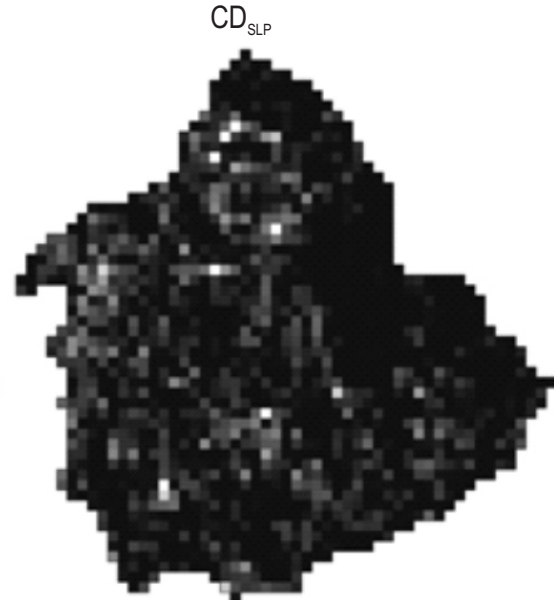

Low value

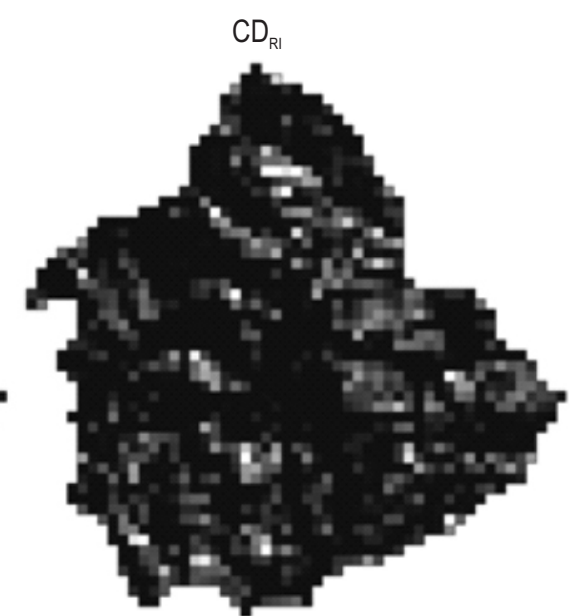

High value

Fig. 2 : The component diversity maps of topographical variables.

first axes of $\mathrm{PCA}_{\mathrm{ALT}}, \mathrm{PCA}_{\mathrm{SLP}}$, and $P C A_{\mathrm{RI}}$ are given in the following equations.

$$
\begin{aligned}
& \mathrm{CD}_{\mathrm{ALT}}=6.0298 \mathrm{H}_{\mathrm{ALT}}+82.009\left(1-\lambda_{\mathrm{ALT}}\right)-75.555 \mathrm{H}_{2 \mathrm{ALT}}-96.402 \\
& \mathrm{CD}_{\mathrm{SLP}}=6.7568 \mathrm{H}_{\mathrm{SLP}}+98.256\left(1-\lambda_{\mathrm{SLP}}\right)-91.221 \mathrm{H}_{2 \mathrm{SLP}}-115.41 \\
& \mathrm{CD}_{\mathrm{RI}}=2.5638 \mathrm{H}_{\mathrm{RI}}+35.578\left(1-\lambda_{\mathrm{RI}}\right)-32.625 \mathrm{H}_{2 \mathrm{RI}}-41.375
\end{aligned}
$$

In which $C D_{A L T}$, $C D_{\text {SLP }}$ and $C D_{R I}$ are the component diversity indices of ALT, SLP and RI, respectively. Using equation $6-8$, the maps obtained from those component diversity measures are illustrated in Fig. 2.

The results of the studies carried out by Vivian-Smith (1997), Dufour et al. (2006), Touré and Ge (2014) and MorzariaLuna et al. (2004) revealed that environmental heterogeneity effects biodiversity, in particular beta diversity and gamma diversity. Therefore, employing the surrogate variables of environmental heterogeneity as explanatory variables is of great importance in creating accurate distribution models of biodiversity.

In other words, the distribution maps of biodiversity are essential information layers to make ecosystem based management plans. Therefore, the more accurate biodiversity maps are obtained, the more successful implementations intended for sustainability of the ecosystems can be generated. The fact that environmental heterogeneity plays a crucial role in the variation of biodiversity and strong distribution models of biodiversity are vital for preparing the accurate ecosystem based management plans means that explanatory variables for modeling of biodiversity should be prepared by considering 
surrogate variables reflecting environmental heterogeneity as well as other environmental variables.

In the present study, first of all, the diversity indices $(\mathrm{H}, 1$ $\lambda, H_{2}$ and $Q$ ) were calculated at each topographical variables for each BIOPIXEL to obtain the maps of the surrogate variables of environmental heterogeneity (topographical diversity maps) (Fig. 1). Next, the correlation analyses were performed to examine interrelationships of those maps. After correlation analyses, it was found very strong relationships among $\mathrm{H}, 1-\lambda$ and $\mathrm{H}_{2}$ maps of all topographical variables. The component diversity equations were, therefore, developed from those diversity measures using the Principle Component Analyses, and those equations were applied to the districts for each of topographical variables.

As a result of the present study, three maps of $Q$ index (Fig. 2) and three component diversity maps derived from $\mathrm{H}, 1-\lambda$ and $\mathrm{H}_{2}$ indices were created for altitude, slope degree and radiation degree at the size of BIOPIXEL. Thus, six surrogate explanatory layers derived from altitude, slope degree and radiation index maps were stored in order to use explanatory variables for further studies dealing with modeling and mapping of biodiversity in the Kuyucak mountain district, Turkey.

\section{Acknowledgment}

We acknowledge the Scientific and Technological Research Council of Turkey (TÜBITAK) which provided financial support to this project (PN:1130495) which entitled "Spatial Modeling of Woody Plant Diversity in the Kuyucak Mountain District".

\section{References}

Aertsen, W., V. Kint, J. Van Orshoven, K. Özkan and B. Muys: Comparison and ranking of different modelling techniques for prediction of site index in Mediterranean mountain forests. Ecol. Model., 221, 1119-1130 (2010).

Ahmadi, M., M. Kaboli, E. Nourani, A. A. Shabani and S. Ashrafi: A predictive spatial model for gray wolf (Canis lupus) denning sites in a human-dominated landscape in western Iran. Ecol. Res., 28, 513-521 (2013).

Arntzen, J.: From descriptive to predictive distribution models: a working example with Iberian amphibians and reptiles. Front. Zool., 3, 9994-9993 (2006).

Blasi, C., M.L. Carranza, R. Frondoni and L. Rosati: Ecosystem classification and mapping: A proposal for Italian landscapes. App. Veg. Sci., 3, 233-242 (2000).

Botta-Dukát, Z.: Rao s quadratic entropy as a measure of functional diversity based on multiple traits. J. Veget. Sci., 16, 533-540 (2005).

Boyden, J., K.E. Joyce, G. Boggs and P. Wurm: Object-based mapping of native vegetation and para grass (Urochloa mutica) on a monsoonal wetland of Kakadu NP using a Landsat 5 TM Dryseason time series. Spatial. Sci., 58, 53-77 (2013).

Brotons, L., W. Thuiller, M.B. Araújo and A.H. Hirzel: Presence-absence versus presence-only modelling methods for predicting bird habitat suitability. Ecography, 27, 437-448 (2004).

Dáttilo, W., J.C. Falcão and M.C. Teixeira: Predictive model of distribution of Atta robusta Borgmeier 1939 (Hymenoptera: Formicidae): subsidies for conservation of a Brazilian leaf-cutting ant endangered species. Stud. Neotro. Fauna Environ., 47, 193-201 (2012).

Dufour, A., F. Gadallah, H.H. Wagner, A. Guisan and A. Buttler: Plant species richness and environmental heterogeneity in a mountain landscape: Effects of variability and spatial configuration. Ecography, 29, 573-584 (2006).

Dymond, C.C. and E.A. Johnson: Mapping vegetation spatial patterns from modeled water, temperature and solar radiation gradients. ISPRS J. Photogra. Rem. Sen., 57, 69-85 (2002).

Filz, K.J. and T. Schmitt: Niche overlap and host specificity in parasitic Maculinea butterflies (Lepidoptera: Lycaenidae) as a measure for potential extinction risks under climate change. Org. Divers. Evol., $15,555-565(2015)$

Franklin, J., K.E. Wejnert, S.A. Hathaway, C.J. Rochester and R.N. Fisher: Effect of species rarity on the accuracy of species distribution models for reptiles and amphibians in southern California (2009).

Grondin, P., S. Gauthier, D. Borcard, Y. Bergeron and J. Noël: A new approach to ecological land classification for the Canadian boreal forest that integrates disturbances. Landsc. Ecol., 29, 1-16 (2014).

Guisan, A. and U. Hofer: Predicting reptile distributions at the mesoscale: relation to climate and topography. J. Biogeogr., 30, 1233-1243 (2003).

Habel, J.C., D. Roedder, S. Stefano, M. Meyer and T. Schmitt: Strong genetic cohesiveness between Italy and North Africa in four butterfly species. Biol. J. Linn. Soc., 99, 818-830 (2010).

Hijmans, R.J., S.E. Cameron, J.L. Parra, P.G. Jones and A. Jarvis: Very high resolution interpolated climate surfaces for global land areas. Int. J. Climatol., 25, 1965-1978 (2005).

Kramer Schadt, S., J. Niedballa, J.D. Pilgrim, B. Schröder, J. Lindenborn, V. Reinfelder, M. Stillfried, I. Heckmann, A.K. Scharf and D.M. Augeri: The importance of correcting for sampling bias in MaxEnt species distribution models. Diversity and Distributions, 19, 1366$1379(2013)$

Lees, B.G. and K. Ritman: Decision-tree and rule-induction approach to integration of remotely sensed and GIS data in mapping vegetation in disturbed or hilly environments. Environ. Manag., 15, 823-831 (1991).

Manel, S., J.M. Dias and S.J. Ormerod: Comparing discriminant analysis, neural networks and logistic regression for predicting species distributions: A case study with a Himalayan river bird. Ecol. Model., 120, 337-347 (1999)

Moisen, G.G. and T.S. Frescino: Comparing five modelling techniques for predicting forest characteristics. Ecol. Model., 157, 209-225 (2002).

Morzaria Luna, L., J. Callaway, G. Sullivan and J. Zedler: Relationship between topographic heterogeneity and vegetation patterns in a Californian salt marsh. J. Veget. Sci., 15, 523-530 (2004).

Munguía, M., A.T. Peterson and V.S. Cordero: Dispersal limitation and geographical distributions of mammal species. J. Biogeogr., 35, 1879-1887 (2008).

Ortega-Huerta, M.A. and A.T. Peterson: Modeling ecological niches and predicting geographic distributions: a test of six presence-only methods. Revista mexicana de Biodiversidad, 79, 205-216 (2008).

Özcelik, H. and M. Korkmaz: Contributions to the flora of Sutculer- 
Isparta (Turkey). Bull. PureAppl. Sci., 21, 1-19 (2002).

Özdamar, K.: Paket Programlar Ille İstatistiksel Veri Analizi 1[In Turkish], Edition Number:1, Kaan Bookshop, Eskişehir (1999).

Özkan, K.: Relationships between tree and shrub species diversity and physiographic site factors in Cariksaraylar site section groups in Beysehir watershed, Anadolu University Publications. J. Sci. Technol., 7, 157-166 (2006).

Özkan, K.: Assessment to the relationships between vegetation and site properties in accordance with similarity values between quadrat pairs. J. Biolog. Diver. Conser., 1, 59-73 (2008).

Özkan, K. and U. Berger: Predicting the potential distribution of plant diversity in the Yukarıgökdere forest district of the Mediterranean region. Pol. J. Ecol., 62, 441-454 (2014).

Özkan, K., S. Gulsoy, A. Mert, M. Ozturk and B. Muys: Plant distributionaltitude and landform relationships in karstic sinkholes of Mediterranean region of Turkey. J. Environ. Biol., 31, 51-60 (2010).

Özkan, K., A. Mert, W. Aertsen and B. Muys: Hierarchical land classification and mapping of Aglasun Forest Ecosystems in the Mediterranean Region, Turkey. J. Environ. Biol., 34, 623-633 (2013).

Özkan, U.Y., I. Ozdemir, S. Saglam, A. Yesil and T. Demirel: Evaluating the woody species diversity by means of remotely sensed spectral and texture measures in the urban forests. J. Indian Soc. Rem. Sen., 1-11 (2016).

Rameshprabu, N. and P. Swamy: Prediction of environmental suitability for invasion of Mikania micranthain India by species distribution modelling. J. Environ. Biol., 36, 565 (2015).

Ray, R., K. Gururaja and T. Ramchandra: Predictive distribution modeling for rare Himalayan medicinal plant Berberis aristata DC. J. Environ. Biol., 32, 725 (2011).

Rao, C.R.: Diversity and dissimilarity coefficients; a unified approach. Theor. Popul. Biol., 21, $24-43$ (1982).

Renyi, A.: On measures of entropy and information. In: Proceedings of the $4^{\text {th }}$ Berkeley Symposium on Mathematical Statistics and Probability (Ed.: J. Neyman). University of California Press, Berkeley, pp. 547-561 (1961).

Ricotta, C.: A note on functional diversity measures. Basic Appl. Ecol., 6 , 479-486 (2005).

Rocchini, D., N. Balkenhol, G.A. Carter, G.M. Foody and T.W. Gillespie: Remotely sensed spectral heterogeneity as a proxy of species diversity: Recent advances and open challenges. Ecol. Inform., 5, 318-329 (2010).

Rocchini, D., L. Delucchi, G. Bacaro, P. Cavallini, H. Feilhauer, G.M. Foody and S. Schmidtlein: Calculating landscape diversity with information-theory based indices: A GRASS GIS solution. Ecolog. Inform., 17, 82-93 (2013).

Sánchez-García, F.J., J. Galián and D. Gallego: Distribution of Tomicus destruens(Coleoptera: Scolytinae) mitochondrial lineages: Phylogeographic insights and niche modelling. Organisms Diver. Evol., 15, 101-113 (2015).

Seoane, J., J. Bustamante and R. Diaz-Delgado: Competing roles for landscape, vegetation, topography and climate in predictive models of bird distribution. Ecol. Model., 171, 209-222 (2004).

Shannon, C.E.: A Mathematical Theory of Communication. The Bell System Technical J., 27, 379-423 (1948).

Simpson, E. H.: Measurement of diversity. Nature, 163, 688 (1949).

Sobek-Swant, S., D.A. Kluza, K. Cuddington and D.B. Lyons: Potential distribution of emerald ash borer: What can we learn from ecological niche models using Maxent and GARP? Forest. Ecol. Manag., 281, 23-31 (2012).

Tognelli, M.F., S.A. Roig-Junent, A.E. Marvaldi, G.E. Flores and J.M. Lobo: An evaluation of methods for modelling distribution of Patagonian insects. Rev. Chil. Hist. Nat., 82, 347-360 (2009).

Touré, D. and J. Ge: The response of plant species diversity to the Interrelationships between Soil and environmental factors in the limestone forests of Southwest China. J. Environ. Earth Sci., 4, 105-122 (2014).

Veech, J.A. and T.O. Crist: Habitat and climate heterogeneity maintain beta diversity of birds among landscapes within ecoregions. Global Ecol. Biogeogr., 16, 650-656 (2007).

Vivian-Smith, G.: Microtopographic heterogeneity and floristic diversity in experimental wetland communities. J. Ecol., 85, 7182 (1997).

Wei, X.Z., M.X. Jiang, H.D. Huang, J.Y. Yang and J. Yu: Relationships between environment and mountain riparian plant communities associated with two rare tertiary-relict tree species, Euptelea pleiospermum (Eupteleaceae) and Cercidiphyllum japonicum (Cercidiphyllaceae). Flora - Morphol. Distrib. Functi. Ecol. Plants, 205, 841-852 (2010).

Whittaker, R.H.: Evolution and measurement of species diversity. Taxon, 21, 213-251 (1972) 